\title{
AGRICULTURA IRRIGADA NO CONTEXTO AMAZÔNICO: UMA ABORDAGEM SISTEMÁTICA DO USO DA ÁGUA EM UMA HORTICULTURA NO MUNICÍPIO DE ALTAMIRA-PA
}

\author{
IRRIGATED AGRICULTURE IN THE AMAZON CONTEXT: A \\ SYSTEMATIC APPROACH TO THE USE OF WATER IN A \\ HORTICULTURE IN THE MUNICIPALITY OF ALTAMIRA-PA
}

\author{
Eliézer Cláudio Ribeiro Silva \\ Universidade do Estado do Pará \\ Fiamma Buchinger Alves \\ Universidade do Estado do Pará \\ Igor Itaci Stesmastchuk da Silva \\ Universidade do Estado do Pará
}

\section{RESUMO}

A agricultura irrigada é uma das atividades humanas que mais utilizam a água, fazendo com que se necessite de uma melhor fiscalização e gestão do uso desse bem público. O objetivo desse estudo foi analisar a gestão do uso da água no município de Altamira-PA, tomando como estudo de caso uma horticultura que abastece esse município, propondo-se também medidas para minimizar os impactos ambientais. A metodologia utilizada teve caráter qualitativo, buscando, através de visitas in loco e o uso do mapeamento, identificar as atividades que exigiam o uso da água, bem como a forma de utilização de agrotóxicos, que podem contaminar este recurso. O empreendimento utiliza até 40 mil litros por dia no período do verão, sendo que a irrigação por aspersão é a que apresenta maiores desperdícios, devido aos efeitos do vento e humidade do ar. A utilização do reservatório de água para a criação da espécie de peixe tilápia (Oreochromis niloticus) torna-se um ponto positivo, pelo fato de reutilizar da água. O sistema de drenagem contido na horticultura não é eficaz, o que o torna um favorecedor dos processos de carreamento de sólidos e agrotóxicos para os recursos hídricos, devido a declividade acentuada do local. A horticultura não apresenta outorga do direito de uso da água, nem o licenciamento ambiental, ambos instrumentos da Política Nacional dos Recursos Hídricos e Política Nacional de Meio Ambiente, respectivamente. É necessário a implantação de uma gestão ambiental eficaz, visando a melhoria da qualidade produtiva e ambiental, sob a ótica do desenvolvimento sustentável.

Palavras-Chaves: Gestão Ambiental, Recursos Hídricos, Sustentabilidade. 


\section{ABSTRACT}

Irrigated agriculture is one of the most human activities that use water, causing need to better control and management of the use of this water resource. The aim of this study was to analyze the management of water use in the city of Altamira-PA, taking as a case study, a horticulture that supplies the municipality, also proposing measures to minimize environmental impacts. The methodology was qualitative, searching through site visits and the use of mapping, identifying the activities that required the use of water as well as use of pesticides, which can contaminate this feature. The development uses up to 40 thousand liters per day in summer time, wherein the sprinkler irrigation is that greater waste, due to the effects of wind and humidity. The use of the water tank to create the kind of fish tilápia (Oreochromis niloticus) becomes a positive, because reuse of the water. The horticulture contained drainage system is not effective, which makes it a favoring of entrainment processes of solids and pesticides to water resources, due to steep slope of the site. Horticulture has not granted the right to use the water or environmental licensing, both instruments of the National Water Resources Policy and the National Environmental Policy, respectively. The implementation of effective environmental management is necessary in order to improve the production and environmental quality from the perspective of sustainable development.

Key words: Environmental Management, Water Resources, Sustainability.

\section{INTRODUÇÃO}

De importância primordial à vida, a água supre as necessidades humanas em suas diversas formas. A exploração hídrica para geração de energia elétrica, navegação, irrigação, abastecimento industrial e doméstico são alguns exemplos que justificam seu imensurável valor a toda humanidade. Entre todos os usos da água, os que tem fins agrícolas são os que demandam os maiores volumes.

O aumento da produtividade dos plantios proporcionado pelo uso da água nas lavouras desperta o interesse do homem até os dias atuais. Conforme FAO (2014) em todo o mundo, $70 \%$ do consumo total de água doce é destinado a agricultura, chegando a 90\% em países subdesenvolvidos, o consumo da área industrial, incluindo a produção de energia, chega a 20\% e o doméstico $10 \%$.

O uso da água de forma desenfreada pode comprometer o recurso hídrico. A quantidade de água em boa qualidade existente no meio ambiente é finita e sua disponibilidade diminui gradativamente devido ao crescimento populacional, à expansão das fronteiras agrícolas e à degradação do meio ambiente. Sendo a água um recurso indispensável à vida, é de fundamental importância a discussão das relações entre o homem e a água, uma vez que a sobrevivência das gerações futuras depende diretamente das decisões que hoje estão sendo tomadas. 
O modelo de desenvolvimento no Brasil, diante do mercado mundial, baseiase na produção rural e de metais. Porto (2009) e Ferreira et al. (2016) exemplificam esse modelo remetendo-se às indústrias siderúrgicas no Sudeste, monoculturas no Sul e Centro-Oeste, cana de açúcar no Nordeste e à pecuária na Amazônia.

No Brasil, os cultivos irrigados representam cerca de $16 \%$ da demanda de alimentos e $35 \%$ do valor de produção, isso significa que cada hectare irrigado equivale a três hectares em produtividade física e a sete em produtividade econômica, quando comparado aos cultivados em condições de agricultura que dependem de chuva (BRITO et al., 2011)

A crise hídrica de 2014 pôs em xeque a questão da gestão das águas no Brasil, tendo algumas regiões marcadas severamente, como o Nordeste e os estados do Minas Gerais, São Paulo e Rio de Janeiro (MACEDO, 2015). A autora ainda afirma que além da necessidade de água para o consumo humano e manutenção do centro urbano, há impactos no campo agrícola, o que reflete na economia e, propriamente, no acesso à alimentação.

Esse estudo tem como objetivo analisar a gestão do uso da água, a partir da agricultura irrigada em uma horticultura no município de Altamira-PA. Buscou-se identificar os impactos sobre os recursos hídricos, bem como a proposição de práticas sustentáveis para a otimização da produção, visando a melhoria qualidade ambiental.

\section{Histórico do uso da água para a irrigação}

Desde o controle das cheias do rio Nilo no Antigo Egito e dos rios Tigre e Eufrates na Mesopotâmia, até o uso de força animal e humana para distribuição da água em tabuleiros cultivados na Índia e China e a construção de canais e terraços em pedra pelos povos andinos e mesoamericanos do período pré-colombiano, a irrigação sempre apresenta-se como prática essencial ao desenvolvimento humano (RODRIGUES e IRIAS, 2004). Os mesmos autores ressaltam que existem estudo arqueológicos que apontam que a agricultura praticada pelo Incas na América do Sul estava associada às práticas de manejo conservacionista complexos para o solo, permitindo a recuperação de áreas degradas pelas atividades agrícolas.

Macedo (2015) relata que o primeiro órgão brasileiro coma função de 
organizar as informações relacionadas à agricultura foi a Secretaria de Estado dos Negócios da Agricultura, Comércio e Obras Públicas11, estabelecida pelo decreto n. 1.067, de 28 de julho de 1860. O autor afirma que a mesma é considerada a instituição que deu origem ao atual Ministério da Agricultura, Pecuária e Abastecimento, com o objetivo de gerar estímulos ao agronegócio no país.

Em relação as primeiras experiências mundiais, a irrigação no Brasil apresentou-se de maneira tardia, não existindo indícios da prática de irrigação pelos índios (BRASÍLIA, 2008). O autor relata que o primeiro projeto de irrigação no Brasil começou em 1881 no Rio Grande do Sul, por iniciativa privada, para suprimento de água utilizada em lavoura irrigada de arroz. Em 25 de junho de 1979 surge o primeiro documento legal sobre a irrigação no Brasil, a Lei ํo 6.662, regulamentada pelo Decreto ํㅜ 89.496 de 29 de março de 1984 (CODEVASF, 2010).

Os dados estatísticos históricos sobre a agricultura irrigada, conforme afirmam Saraiva e Souza (2012), pode conter alguns equívocos, deixando-os abertos às diferentes interpretações. Rosa e Hebel Júnior (2015) relatam que o censo agropecuário foi aprimorado ao longo do tempo, sendo que a partir de 1975, o mesmo passou a identificar alguns métodos de irrigação (mas sem considerar a rega manual); fato que só mudou a partir de 1996. A partir de 2006, afirmam os mesmos autores, o censo incorporou técnicas modernas de irrigação (localizada e por pivô), considerando também a rega manual.

\section{Agricultura irrigada na Região Amazônica Brasileira: o Estado da Arte}

De acordo com Rodrigues e Irias (2004), no Brasil desenvolveu-se uma cultura de mau uso e desperdício de água, baseada em concepções antigas de que a água é um recurso abundante e facilmente renovável. É sabido que a água está disponível em grande quantidade no país, porém a qualidade da mesma pode enquadrar-se em diferentes padrões de uso (baseando-se na Resolução CONAMA ํo 357/2005 e 430/2011).

Tal comportamento apresenta-se divergente da realidade do país, pois, conforme afirma ANA (2014), a visão de abundância de água no Brasil é enganosa, devido a desproporcionalidade em sua distribuição: $81 \%$ do recurso hídrico está 
concentrado na Região Hidrográfica Amazônica, onde está a menor demanda e contingente populacional, cerca de $5 \%$ da população brasileira, e apenas $2,7 \%$ dos recursos hídricos do Brasil estão disponíveis para regiões hidrográficas banhadas pelo Oceano Atlântico, que concentram $45,5 \%$ da população.

Os métodos de irrigação são os modos artificiais de como a água é introduzida na agricultura. Andrade e Brito (2010), classificam em quatro, os tipos de irrigação: superfície, aspersão, localizada e subirrigação. Os mesmos afirmam que pivô central é um tipo de irrigação por aspersão e pode ser utilizado para irrigar áreas de até 177 ha. Esse sistema possui uma alta capacidade de irrigação, corroborando para o aumento da produtividade, porém demanda muito água; o que acaba por tornar-se uma limitação (SANTOS, 2010).

Os dados da ANA e EMBRAPA/CNPMS (2016) apontam 19,9 mil pivôs centrais de irrigação ocupando uma área total de 1,275 milhão de hectares no ano de 2014. Os mesmos concluíram que $80 \%$ da área ocupada por pivôs centrais no Brasil são oriundos dos estados de São Paulo, Bahia, Minas Gerais e Goiás. Na divisão hidrográfica nacional, destacam-se maiores áreas ocupadas por pivôs nas regiões Tocantins-Araguaia e São Francisco e nas bacias dos rios Grande, Paranapanema e Paranaíba (ambas na região hidrográfica do Paraná).

O Gráfico 1 apresenta os dados dos pivôs centrais de irrigação, classificados pelas bacias hidrográficas do Brasil. Nota-se que a bacia Amazônica apresenta apenas 43, 853 pivôs de irrigação por hectare, representando 3,44\% do total do Brasil. Já a bacia do Paraná, representa sozinha 41,3\% (562,484 pivôs/ha) do total no país. 
Gráfico 1: Áreas ocupadas por pivôs centrais de irrigação por regiões hidrográficas no Brasil.

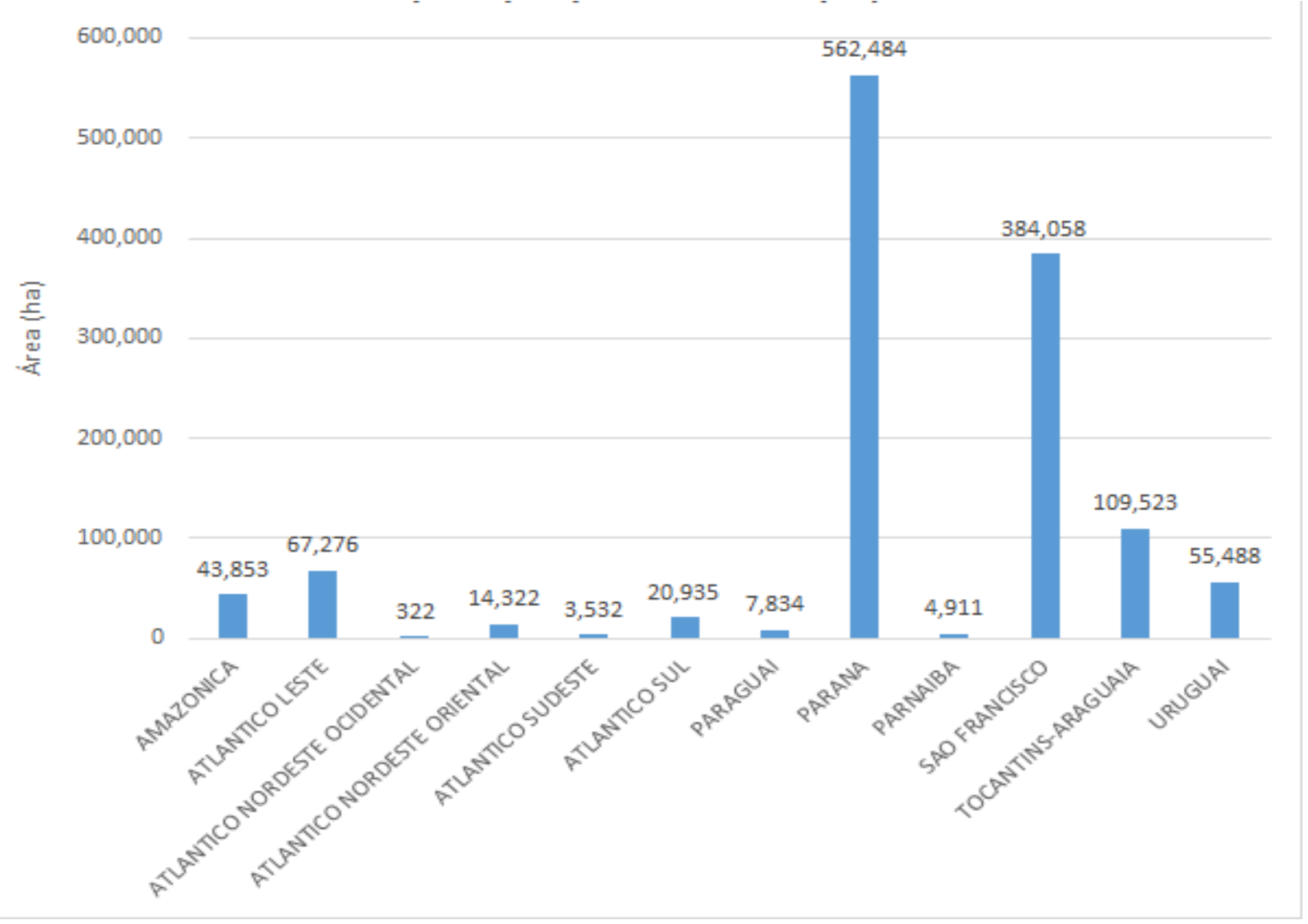

Fonte: Adaptado de ANA e Embrapa/CNPMS (2016).

\section{MATERIAL E MÉTODOS}

O presente trabalho trata-se de um estudo de caso, de caráter qualitativo, em um empreendimento com atividade de agriculta de hortaliças, no município de Altamira-PA. O mesmo está localizado sob as coordenadas geográficas do perímetro: Y1: 393'23.79"S e X1: 5295'6.28”O, Y2: 393'24.77"S e X2: 52'15'9.93"O, Y3: 393'32.55"S e X3: 52915'7.54"O e Y4: 393'29.50"S e X4: 5295'0.12"O; a 1,5 km do perímetro urbano (sentido do município de Brasil Novo), tendo uma dimensão de 6,162 ha $\left(61.625 \mathrm{~m}^{2}\right)$. 
Figura 1: Mapa de Localização da Horticultura.

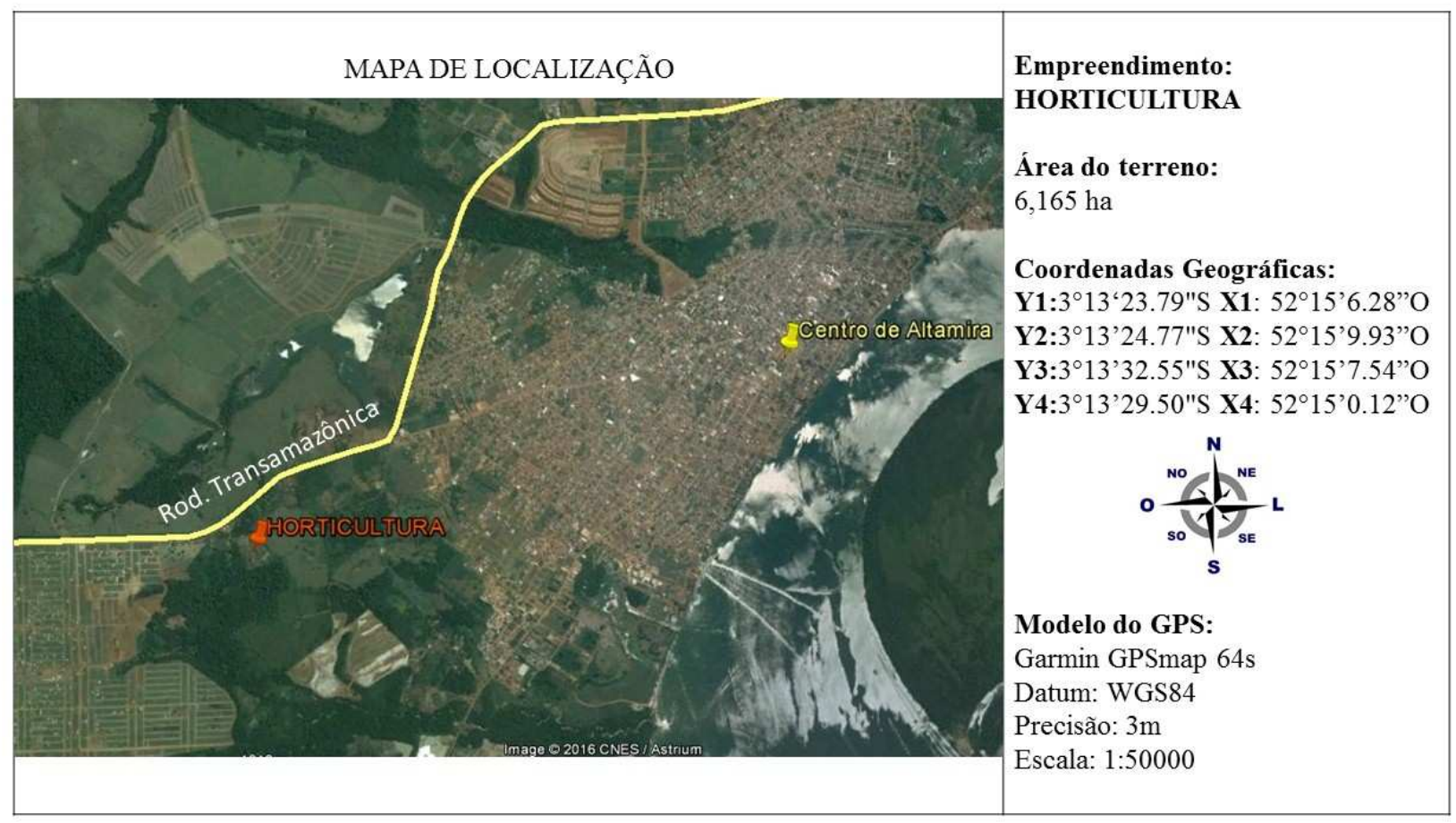

Fonte: Própria

A análise do uso da água na agricultura irrigada na horticultura foi realizada com base em um levantamento bibliográfico para a coleta de dados, a partir de fontes atuais, de fontes oficiais e revistas especializadas, com a busca de termos chave relacionando ao estudo, sem esquecer das referências clássicas à cerca do assunto, levando em consideração teorias e metodologias já existentes.

As informações de campo à do uso da água e do processo produtivo foram levantadas por meio de uma visita in loco, realizando-se, também, um questionário como proprietário e funcionários. Utilizou-se um GPS (modelo Garmim GpsMap 64s, sistema de projeção UTM - DATUM WGS84) para a delimitação do perímetro da horticultura, o qual foi inserido no software Google Earth para confecção de mapas e foi feito o registro fotográfico da área produtiva. 


\section{RESULTADOS E DISCUSSÃO}

Há mais de 15 anos, a Horticultura analisada neste estudo vem desenvolvendo suas atividades, a qual produz hortaliças voltadas para o atendimento a demanda do município de Altamira. A Figura 2 demonstra o arranjo geral do empreendimento, que encontra-se com culturas bastantes diversificadas, como: pepino, berinjela, coentro, alface, cebolinha, rúcula, milho, quiabo e jiló.

Figura 2: Croqui do Empreendimento.

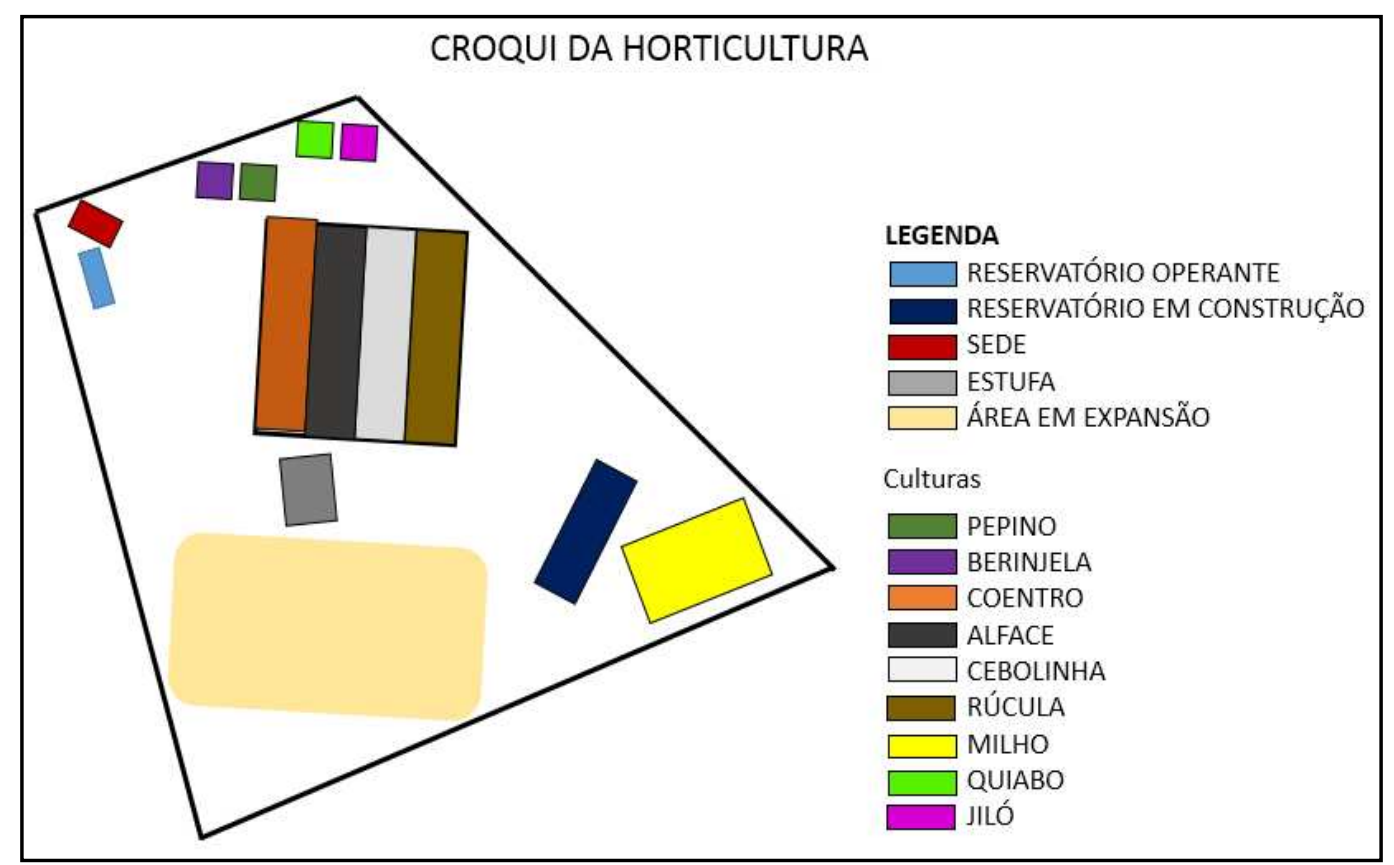

Fonte: Própria

A horticultura possui dois reservatórios de água de 40 mil litros cada (Figura 4), porém está em uso apenas um, pois o outro ainda não está em funcionamento, devido estar em fase final de instalação. O horário de irrigação das plantações é controlado, sendo realizado no começo da manhã, meio dia e no fim da tarde, tendo um consumo de 5 mil litros de água por dia durante o inverno e 40 mil por dia durante o verão. Esse fato denota que o modo de utilização da água na técnica no presente local é ordenado, logo, evita o uso desnecessário da água. Porém devese destacar a grande quantidade de água demandada para essa atividade.

O tipo de irrigação utilizada na horticultura é por aspersão convencional (figura 3a), por gotejamento (figura 3b) e no viveiro de mudas é utilizado rega 
manual (Figura 3c). Os canais de irrigação sempre passam por manutenção e reparação assim que apresentam algum defeito, isso evita o desperdício de água ao longo do percurso e otimiza o processo de irrigação.

Os efeitos do clima podem afetar o método de irrigação por aspersão, pois, ao fracionar a água em gotículas, torna-as suscetíveis ao arraste pelo vento e à evaporação, quando inseridas em clima seco. Segundo Azevedo et al. (1999) o desperdício de energia na irrigação aumenta com a diminuição da umidade relativa do ar e com o aumento da velocidade do vento, da radiação solar e da pressão de operação do aspersor.

Figura 3: Tipos de irrigação utilizados no empreendimento.

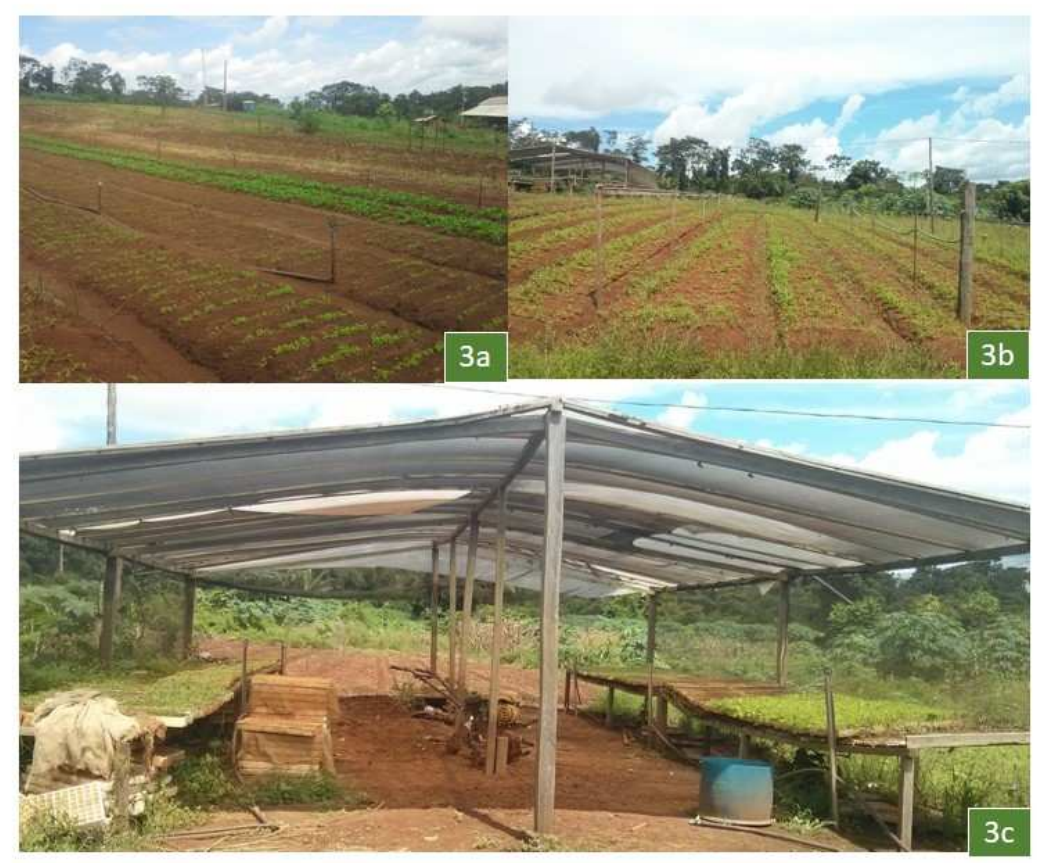

Fonte: Própria

O emprego de produtos químicos na agricultura irrigada, como os fertilizantes e agrotóxicos, gera um passivo ambiental nesse processo, visto que por meio do escoamento superficial a água leva consigo esses elementos tóxicos, tendo como destino final os rios e os depósitos subterrâneos, implicando na sua contaminação (ALMEIDA e COSTA, 2014). Como a horticultura utiliza adubo químico no solo, é imprescindível atenção máxima quanto à utilização da água juntamente com um sistema de drenagem eficaz, que favoreça uma maior infiltração da água no solo. Outro problema gerado, segundo Almeida e Costa 
(2014), é a fragmentação dos materiais do solo, logo, a erosão do mesmo, afetando, dessa forma, a sua produtividade.

Um dos problemas da irrigação é o processo de salinização. Sua ocorrência é consequência direta da relação entre infiltração e evaporação, ou seja, quando a infiltração for mais intensa que a evaporação, os compostos são lixiviados e o solo se acidifica e inversamente, quando predomina a evaporação, os sais são depositados na camada superficial, salinizando-a (PRIMAVESI, 1979). A horticultura apresenta um uso controlado da água na irrigação por aspersão, fazendo-o gradualmente até que a infiltração por completo ocorra. Quanto maior for a eficiência de aplicação da irrigação, menor será a lâmina de água aplicada e, como consequência, menor será a quantidade de sal conduzida para a área irrigada, bem como o volume de água percolado e drenado (BERNARDO, 2008).

O desmatamento é outro problema acarretado pela prática da agricultura irrigada, já que o mesmo consiste na retirada da vegetação de uma determinada área, que pode alterar a microflora e fauna regional, a produção de peixes, a população de insetos e as condições de erosão e de sedimentação na bacia hidrográfica. A área da horticultura apresenta um ponto positivo sobre esse aspecto, pois áreas de florestas a volta do empreendimento estão sendo conservadas, formando o chamado "cinturão-verde".

O tanque de armazenamento de água para irrigação da horticultura também é utilizado para piscicultura de tilápia (Oreochromis niloticus). Segundo Gomes et al. (2012) o reuso da água da piscicultura com a tilápia, viabiliza a utilização dos recursos hídricos e a exploração agrícola, com a obtenção de duas receitas a partir do uso compartilhado da água, obtendo com isso, altos índices de lucratividade.

Nas análises de Lopes et al. (2012), os valores encontrados para cada parâmetro, na água de piscicultura, evidenciam o potencial reuso desta, pois estes estão dentro dos limites estabelecidos pela legislação. Ainda conforme o autor, diante da crescente busca pelo desenvolvimento sustentável e visando atender à demanda por água, vê-se o reuso do recurso uma ótima opção para suprir a demanda de águas para irrigação, pois somente na área experimental estudada por eles, cerca de 135.000 litros são descartados a cada ciclo de vida dos peixes, sendo que poderiam ser reaproveitadas para qualquer tipo de cultura irrigada.

Conforme o CONAMA 357/2005, o uso da água na horticultura se enquadra em Águas Doces - Classe 2, servindo para: "à irrigação de hortaliças, plantas 
frutíferas e de parques, jardins, campos de esporte e lazer, com os quais o público possa vir a ter contato direto". Essa atividade deve fazer uso e manejo sustentável dos solos e dos recursos hídricos, seguindo os princípios da Política Nacional de Irrigação (Lei no 12.787/2013).

Com base na Lei no 9.433/1997, que institui a Política Nacional do Recursos Hídricos (PNRH) para que se possa retirar a água de qualquer fonte natural, necessita-se da autorização de algum órgão federal, estadual ou municipal, por meio da outorga do direito de uso da água, que determinará uma vazão máxima a ser utilizada, além das medidas ambientais para a conservação dos mananciais (ALBUQUERQUE, 2004). O empreendimento em questão não possui outorga do uso de direito da água, contrariando o princípio do usuário-pagador e poluidor pagador. De acordo com o princípio "poluidor-pagador", se todos têm direito a um ambiente limpo, deve o poluidor pagar pelo dano que provocou e segundo o princípio "usuário-pagador", paga-se pela utilização da água, em detrimento dos demais (GRANZIERA, 2000).

A outorga é importante para o Cadastro Nacional de Recursos Hídricos (CNRH), visando a quantificação do uso da água e fornecendo subsídios financeiros para os órgãos aplicarem à gestão sustentável da água. No Pará, a Secretaria de Meio Ambiente e Sustentabilidade (SEMAS), por meio da Política Estadual de Recursos Hídricos (Lei Estadual 6.381/2001), é o órgão responsável pela gestão dos recursos hídricos no estado. Um dos instrumentos dessa lei é o Sistema Estadual de Informações dos Recursos Hídricos (SEIRH), que tem por finalidade a coleta, o tratamento, o armazenamento e a disseminação de informações sobre recursos hídricos e fatores intervenientes à sua gestão, compatibilizados com o Sistema Nacional de Informação sobre Recursos Hídricos SNIRH.

No que se refere ao licenciamento ambiental da horticultura, é de competência da secretaria municipal de meio ambiente fiscalizar e fazer a cobrança da mesma. Segundo a Resolução COEMA no 120/2015, que dispões sobre as atividades de impacto ambiental local, de competência dos Municípios, a atividade de horticultura enquadra-se conforme o Quadro 1: 
Quadro 1: Enquadramento da atividade de horticultura para licenciamento ambiental.

\begin{tabular}{|l|l|l|l|l|l|l|}
\hline \multirow{2}{*}{ Tipologia } & \multicolumn{4}{|l|}{ Porte do Empreendimento } & Potencial \\
\cline { 2 - 6 } & Unidade & Micro & Pequeno & Médio & Grande & Poluidor/Degradador \\
\hline $01-$ Agricultura, Pecuária e Serviços Relacionados em Áreas Consolidadas \\
\hline $\begin{array}{l}\text { Cultura de } \\
\text { Ciclo Curto }\end{array}$ & AUH & $\leq 300$ & $\begin{array}{l}>300 \\
500\end{array}$ & $\begin{array}{l}>500= \\
1.000\end{array}$ & $\begin{array}{l}>1.000 \\
=2.000\end{array}$ & II \\
\hline
\end{tabular}

Fonte: Adaptado de Resolução COEMA oㅜ 120/2015.

A atividade de horticultura classifica-se como cultura de ciclo curto, pois a maioria dos tipos de hortaliças alcançam rapidamente a fase de colheita (máximo de 2 meses para a maioria do estudo de caso). A mesma ainda tem o porte médio, pois a Área Útil (Ha), fica abaixo de 300 ha, possuindo também o potencial poluidor II (que vai de I a III). Portanto, fica evidente a necessidade de se fazer o licenciamento ambiental da horticultura estudada, para minimizar, controlar e mitigar os efeitos dos impactos ambientais negativos causados pela mesma.

De acordo com Christofidis (2002), é necessária uma atenção especial no que se refere à modernização tecnológica, pois máquinas, equipamentos, tubulações e implementos devem ser adequados às áreas a serem irrigadas e às reais possibilidades financeiras do agricultor. $O$ autor ainda afirma que é necessário a substituição dos métodos de irrigação de baixa eficiência por equipamentos e tecnologias que permitam melhor manejo e maior controle da utilização dos recursos hídricos.

Com a implantação de uma gestão ambiental eficiente na horticultura é possível otimizar a produção e diminuir os impactos ambientais, principalmente no que diz respeito a água. A partir dessa ferramenta é possível desenvolver dentro do empreendimento técnicas que contribuirão ao meio ambiente e ao rendimento da produção, como o aproveitamento da água da chuva para encher os reservatórios, com sistemas simples de calha; sistema de gotejamento, que se mostra mais eficiente em comparação a outros métodos; e o esgoto tratado para fins agrícolas. 


\section{CONCLUSÃO}

Os passivos ambientais oriundos da agricultura irrigada devem ser geridos por meio de uma visão holística, multifacetada e íntegra, aplicando a legislação vigente e envolvendo todos os atores que fazem parte do processo desde a produção ao consumidor final. Os diversos compartimentos ambientais (solo, atmosfera, água, seres vivos) devem estar inseridos no planejamento da utilização dos recursos hídricos para irrigação.

Apesar de os benefícios proporcionados pela irrigação sejam inegáveis, os projetos podem trazer impactos adversos a qualidade do solo, da água e ao meio ambiente, em suas variáveis físicas, químicas e sociais, podendo influenciar até mesmo na economia da região. Portanto, se estes forem mal dimensionados e mal manejados podem provocar graves impactos ambientais. Um sistema de irrigação eficiente na agricultura minimiza os riscos do empreendimento, tornando-o mais produtivo e corroborando para a qualidade ambiental

\section{REFERÊNCIAS}

ALBUQUERQUE, P. E. P. Aspectos conceituais do uso eficiente da água na agricultura. In: SIMPÓSIO NACIONAL SOBRE O USO DA ÁGUA NA AGRICULTURA, 2004, Passo Fundo. Anais... 2004. Passo Fundo, 2004. p.1-17.

ANA e Embrapa/CNPMS (2016). Levantamento da Agricultura Irrigada por Pivôs Centrais no Brasil - ano 2014 . Disponível em: $<$ http://metadados.ana.gov.br/geonetwork/>. Acesso em: 15 mai. 2016.

ANDRADE, C. de L.; BRITO, R. A. L. Cultivo de milho: Irrigação. Embrapa, 2010. Disponível em: $<$ http://www.cnpms.embrapa.br/publicacoes/milho $6 \mathrm{ed} /$ imetodos.htm $>$. Acesso em: 14 mai. 2016.

AZEVEDO, H. J. et al.; Influência de elementos do clima no desperdício de energia em um sistema de irrigação por aspersão de alta pressão. Revista Brasileira de Engenharia Agrícola e Ambiental, Campina Grande, v.3, n.3, p.336-341. 1999.

BRASÍLIA. COMPANHIA DE DESENVOLVIMENTO DOS VALES DO SÃO FRANCISCO E DO PARNAÍBA - CODEVASF. Histórico da Irrigação no Brasil. $2010 . \quad$ Disponível em: $<$ http://www2.codevasf.gov.br/programas acoes/irrigacao/historico-da-irrigacao-nobrasil/>. Acesso em: 15 mai. 2016. 
BRASÍLIA. Ministério da Integração Nacional. Secretaria de Infra-estrutura Hídrica. A Irrigação no Brasil: Situação e Diretrizes. Brasília: Gráfica e Editora Esperança, 2008. $113 \quad$ p. Disponível em: $<$ http://www.mi.gov.br/documents/10157/3672008/A+irrigacao+no+Brasil++diretrizes.pdf/b88c745b-f5b3-4f3d-b375-483033a2e80c >. Acesso em: 16 mai. 2016.

BRASIL. Lei oㅜ 9.433, de 8 de janeiro de 1997. Presidência da República, Casa Civil. Brasília, 1997. 2001. . Lei Estadual no 6.381 de 25 de julho de 2001. Palácio do Governo. Belém, Resolução CONAMA no 357, de 17 de março de 2005. DOU, Brasília, n. 053, p.58-63. 2005.

Lei oㅡ 12.787, de 11 de janeiro de 2013. Presidência da República, Casa Civil. Brasília, 2013.

PARÁ. Resolução COEMA no 120, de 28 de outubro 2015. Plenário Do Conselho Estadual De Meio Ambiente, Belém. 2015.

BRITO, L. T. de L.; MELO, R. F. de; GIONGO, V. Impactos ambientais causados pela agricultura no Semiárido brasileiro. Petrolina: Embrapa Semiárido, cap. 5, p.137-169. 2010.

CHRISTOFIDIS, D. Irrigação, a fronteira hídrica na produção de alimentos. Revista ITEM - Irrigação \& Tecnologia Moderna, n.54, v.2, p.46-55. 2002.

DE ALMEIDA, J. J. G.; DA F. R. Análise dos impactos socioeconômicos e ambientais da agricultura irrigada no perímetro irrigado de Pau dos Ferros (RN). Revista Geografares, [S.I], no16, p.22-44. 2014

DOS SANTOS, R. R. Irrigação como alternativa de sustentabilidade agrícola e ambiental. Revista Multidisciplinar Da UNIESP, São Paulo, n.10, p.68-76. 2010.

FERREIRA, M. J. Marcelo et al. Gestão e uso dos recursos hídricos e a expansão do agronegócio: água para quê e para quem? Ciência e saúde coletiva, Rio de Janeiro, v. 21, n. 3, p. 743-752, mar. 2016.

Food and Agriculture Organization of the United Nations- FAO, 2014. The State of World Fisheries and Aquaculture 2014. Rome. 223 pp.

GOMES, E. R.; D'ALBUQUERQUE JUNIOR, B. S.; DE BRITO, R. R. Análise econômica no uso da água de piscicultura na irrigação da banana. In: FORUM AMBIENTAL DA ALTA PAULISTA, 8. 2012. Anais... São Paulo, p-1-6. 2012.

GRANZIEIRA, M. L. M. A cobrança pelo uso da água. Revista CEJ, Brasília, n. 12, p. 71-74. 2000. 
LOPES, I. et al. Potencial do reuso da água de piscicultura da Estação experimental da UNIVASF na irrigação. In: Workshop Internacional, 2., 2012. Anais... [S.I], 2012.

MACEDO, M. F. S. Técnicas de irrigação, o desenvolvimento da agricultura e do agronegócio: uma análise à luz da proteção humana e da cidadania frente à crise hídrica nacional. Campo Jurídico, Barreiras, v.3, n.2, p.39-54, 2015.

PARRY, M. M.; SILVA, M. M; SENA, I. S.; OLIVEIRA, F. P. M. Composição florística da arborização da cidade de Altamira, Pará. Revista da Sociedade Brasileira de Arborização Urbana, Piracicaba, v.7, n.1, p.143-158. 2012.

PORTO, M. F. Conferência Nacional de Saúde Ambiental: cadernos de textos. Desenvolvimento, Conflitos Socioambientais, Justiça e Sustentabilidade: desafios para a transição. In: GT Saúde e Ambiente da Abrasco, organizadores. Conferência Nacional de Saúde Ambiental: caderno de textos. Brasília: Abrasco; 2009. p. 84-91.

PRIMAVESI, A. Manejo Ecológico do Solo: a agricultura em regiões tropicais. São Paulo: Nobel, 1979.

RODRIGUES, G. S.; IRIAS, L. J. M. Considerações sobre os Impactos Ambientais da Agricultura Irrigada. Circular Técnica: Embrapa, Jaguariúna, p.1-7. 2004.

ROSA, J. A.; HEBEL JÚNIOR, C. Estado da Arte da Agricultura Irrigada no Paraná. In: Congresso Nacional de Irrigação e Drenagem, 25., 2015. Anais... São CristovãoSE. 2015.

SARAIVA, K. R.; SOUZA, F. de. Estatísticas sobre irrigação nas regiões sul e sudeste do Brasil, segundo o Censo Agropecuário 2005-2006. Irriga, Botucatu, v.17, n.2, p.168-176, 2012. 